\title{
Outcome of Labour in Nullipara at term with unengaged vertex
}

\author{
Dayal $\mathbf{S}^{1}$, Dayal $\mathbf{A}^{2}$ \\ ${ }^{1}$ Dr Sheetal Dayal, Assistant Professor in Obstetrics and gyenecology, ${ }^{2}$ Dr Achleshwar Dayal, Associate professor in Surgery. \\ Both are affiliated with L N Medical College \& Associated J K Hospital, Bhopal, MP, India
}

Address for correspondence: Dr Sheetal Dayal, Email: dradayal@yahoo.com

\begin{abstract}
Introduction: Engagement of head is most important event in labour which decides obstetric and neonatal outcome. Primigravida is considering important obstetric risk factor. Similarly unengaged head at term should be regarded as high risk case. Present study was conducted to determine the outcome of labour in nulliparous with unengaged head. Methods: It was a case control study conducted in teaching hospital of central India. In the study period, 442 booked cases were studied, among which 214 cases were primigravidae (cases) and 228 cases were multigravidae. Results: In the present study, among primigravidae $189(88.31 \%)$ cases were unengaged at the onset of early labour. In the present study $155(72.42 \%)$ cases presented at -3 station at the onset of labour. Most of them ( $85 \%)$ delivered by Normal delivery. when engagement occurred at the onset of early labour $92 \%$ of patients delivered by normal delivery. When head did not engaged almost $22 \%$ of deliveries required instrumental or operative procedures. Mean birth weight was 2.065 in engaged group while 2.77 in unengaged group. Conclusion: In nulliparous patients a high station at the onset of labour is not necessarily an omnious finding, even though the incidence of arrest disorders are higher when station is -3,or floating, obstetricians can still be optimistic towards vaginal delivery.
\end{abstract}

Key words: Primigravidae, engagement of head, delivery, LSCS, Head station

\section{Introduction}

Engagement has been defined as passage of biparietal diameter of fetal skull through the plane of the pelvic inlet. The sign of a high head at term in primigravidae is not a welcome finding and calls for investigation as to possible causes, certainly many obstetricians take a pessimistic attitude towards eventual vaginal delivery, if the foetal head is not engaged at the onset of labour

Although the engagement of the foetal head is usually regarded as a phenomenon of labour, in nulliparas it commonly occurs during the last few weeks of pregnancy [1]. When it does so, it is confirmatory evidence that pelvic inlet is adequate for that foetal head. Failure of the foetal head to engage in early labour is a greater indicator of operative birth [2].

Traditionally "engagement of fetal head is said to take place usually by 36 weeks of gestation and should remain well engaged from that date onwards" [3]. Engagement has been defined as passage of biparietal diameter of fetal skull through the plane of the pelvic inlet. The sign of a high head at term in primigravidae is not a welcome finding and calls for investigation as to

Manuscript received: $15^{\text {th }}$ Jan 2014

Reviewed: $05^{\text {th }} \mathrm{Feb} 2014$

Author Corrected: $13^{\text {th }}$ Feb 2014

Accepted for Publication: $01^{\text {st }}$ Mar 2014 possible causes, certainly many obstetricians take a pessimistic attitude towards eventual vaginal delivery, if the foetal head is not engaged at the onset of labour [4]

Present study was carried out to find out the incidence of engagement of fetal head in primigravidae at the time of onset of labour, frequency distribution of duration of gestation at first reported engagement and to see the effectof engaged and unengaged fetal head on the onset and outcome of labour.

\section{Materials \& Method}

The present study is a "prospective" study which is conducted in tertiary care teaching hospital of South India for 15 months.

In the study period, 442 booked cases were studied, among which 214 cases were primigravidae and 228 cases were multigravidae.

In this study, pregnant woman attending out patient's department are examined once in every 15 days from 28 weeks onward. After 36 weeks frequency was increased to weekly till delivery. 


\section{Criteria for Engagement}

\section{Abdominal:}

- The presence of no more than 1-fifth of fetal head palpable above the level of pelvic brim.

- At the level of 1-fifth of fetal head palpable above the brim, only sinciput can be felt.

Vaginal:

- $\quad$ The presence of bony presenting part at the level of ischial spines, provided no poles are palpable per abdomen.

\section{Moulding:}

- Zero when the parietal bones at the sagittal suture were separated

- $\quad+$ when the parietal bones were applied to each other but not overlapping

- ++ when the parietal bones overlapping but could be reduced with digital pressure

- +++ when overlapping parietal bones were irreducible

\section{Caput:}

\section{Research Article}

- Graded subjectively on scale from zero for no caput to +++ for severe swelling of scalp.

\section{Inclusion Criteria:}

- Sure of dates, regular cycles.

- Uterine size corresponding to the calculated period of gestation

- $\quad$ Singleton pregnancy

\section{Exclusion Criteria:}

- Not sure of dates

- Multiple gestation

- $\quad$ Breech $>32$ weeks

- Notes which are inappropriate

Vague terms are used rather than engagement like "fixed" or "engaging"

\section{Observations \& Results}

In the present study, total numbers of booked cases studied were 442 cases, out of which 214 cases were primigravidae and 228 were multigravidae.

Table No. 1 - Age wise distribution of patients

\begin{tabular}{|l|l|l|}
\hline Age Group & No of Patients & Percentage \\
\hline$<\mathbf{1 9}$ Years & 28 & 6.33 \\
\hline $\mathbf{2 0 - 3 5}$ & 313 & 70.81 \\
\hline$>\mathbf{3 5}$ & 101 & 22.85 \\
\hline & $\mathrm{N}=442$ & 100 \\
\hline
\end{tabular}

In the present study, 313 cases were in age group 20 to 34 years, which comprises $70.81 \%$ of total, number of teenage pregnancies were $28(6.33 \%)$ in the study. Nearly one fourth of pregnancies were more than 35 years of age. $48.41 \%$ of cases were primigravidae and $51.58 \%$ were multigravidae.

Table No 2: Duration of active phase of labour in head engaged and unengaged in early labour in Primigravidae

\begin{tabular}{|l|l|l|l|l|l|l|}
\hline \multicolumn{2}{|l|}{ Patient group } & \multicolumn{4}{l|}{ Duration of active phase } & \multicolumn{2}{l|}{$12-24 \mathrm{hrs}}$. \\
\hline & \multicolumn{2}{|l|}{} & $<12 \mathrm{hrs}$ & $\%$ & No. & $\%$ \\
\hline Engaged & No. & $\%$ & No. & $\%$ & 2 & 8 \\
\hline Unengaged & 25 & 11.68 & 23 & 92 & 8 & 4.23 \\
\hline
\end{tabular}

In the present study, among primigravidae $189(88.31 \%)$ cases were unengaged at the onset of early labour. In this group $95.78 \%$ had duration of active phase less than 12 hours and $4.2 \%$ of cases had duration of labour more than 12 hours but less than 24 hours. 
Table No 3: Station at onset of labour with mode of delivery in Primigravida

\begin{tabular}{|l|l|l|l|l|l|l|}
\hline & \multicolumn{5}{|c|}{ Station at onset of labour } \\
\hline Mode of Delivery & Floating & -3 & -2 & -1 & No. & $\%$ \\
\hline Normal Delivery & 9 & 131 & 24 & 7 & $\mathrm{n}=171$ & $79.9 \%$ \\
\hline Vaccum & 0 & 9 & 0 & 0 & $\mathrm{n}=9$ & $4.2 \%$ \\
\hline Forceps & 0 & 2 & 0 & 0 & $\mathrm{n}=2$ & $0.93 \%$ \\
\hline LSCS & 12 & 13 & 6 & 1 & $\mathrm{n}=32$ & $14.95 \%$ \\
\hline No. & $\mathrm{N}=21$ & $\mathrm{~N}=155$ & $\mathrm{~N}=30$ & $\mathrm{~N}=8$ & $\mathrm{~N}=214$ & \\
\hline Percentage & $9.81 \%$ & $72.42 \%$ & $14.01 \%$ & $3.73 \%$ & & \\
\hline
\end{tabular}

In the present study $155(72.42 \%)$ cases presented at -3 station at the onset of labour, in these cases $50.96 \%$ engaged within 4 hours of onset of labour, and $36.77 \%$ engaged between 4 to 8 hours of labour.

Most of them ( $85 \%)$ delivered by Normal delivery. 7(4.51\%) cases who presented with -3 station at the onset of labour engagement did not occur.

$21(9.81 \%)$ cases among primigravidae presented with floating head at onset of labour, among them 6 cases $(28.57 \%)$ remained unengaged, 6 cases (28.57\%) engaged within 4 hours of labour, 1 case (4.76\%) engaged after 12 hours of labour.

Table No 4: Mode of delivery with engagement of fetal head in early labour In Primigravidae

\begin{tabular}{|l|l|l|l|l|}
\hline & Engaged & \multicolumn{2}{l|}{ Unengaged } \\
\hline & No. & $\%$ & No. & $\%$ \\
\hline Normal vaginal delivery & 23 & 92 & 148 & 78.30 \\
\hline Forceps & 0 & 0 & 2 & 1.05 \\
\hline Vacuum & 0 & 0 & 9 & 4.76 \\
\hline C-section & 2 & 8 & 30 & 15.87 \\
\hline & 25 & 100 & 189 & 100 \\
\hline
\end{tabular}

Table depicted that when engagement occurred at the onset of early labour $92 \%$ of patients delivered by normal delivery. When head did not engaged almost $22 \%$ of deliveries required instrumental or operative procedures.

Table No 5: Indication of L SCS with station at onset of labour

\begin{tabular}{|l|l|l|l|l|}
\hline Indication of LSCS & \multicolumn{4}{|l|}{ Primigravida } \\
\hline & $5 / 5$ & -3 & -2 & -1 \\
\hline Arrest of Descent & 3 & 6 & 4 & 1 \\
\hline Arrest of Dilatation & 5 & 6 & 2 & - \\
\hline Failed Induction & 1 & - & - & - \\
\hline Failed Inst. Delivery & - & - & - & 1 \\
\hline C.P.D & - & 1 & 2 & - \\
\hline Fetal Distress & 1 & 2 & 3 & - \\
\hline M.S.A.F & 4 & 3 & 2 & - \\
\hline
\end{tabular}

In the study group comprising of primigravidae 14 cases $(43.75 \%)$ had L.S.C.S for arrest of descent and 13 cases (40.62\%) had L.S.C.S for arrest of dilatation. C.P.D was the indication in 3 cases $(9.37 \%)$

Table No 6: Comparison of mean birth weight with engagement in Primigravida

\begin{tabular}{|l|l|l|}
\hline & Engaged & Unengaged \\
\hline Mean birth wt & $2.065 \mathrm{~kg}$ & $2.77 \mathrm{~kg}$ \\
\hline
\end{tabular}

Mean birth weight was 2.065 in engaged group while 2.77 in unengaged group. $(p=0.001$, significant $)$ 


\section{Discussion}

In India like other developing countries home deliveries are common. Nalliparous patients with unengaged head at the time of delivery is consider additional reisk factor for operative delivery. These patients needs more investigation and follow up at the time of labour and delivery. Therefore these patients should be referred to hospitals that are having operative and investigation facilities. Present study was carried out to study effect of unengaged head on obstetric and fetal outcome.

In the study period head was unengaged at the onset of labour in almost $88 \%$ of patients. Our results were comparable with other studies [5-9]

Table 7: Showing prevalence of head engagement in other studies at the onset of labour

\begin{tabular}{|l|l|l|}
\hline & Engaged head & Unengaged head \\
\hline Lakshmi.I 1984 $^{\mathbf{5}}$ & $15.34 \%$ & $84.66 \%$ \\
\hline Sadiqua.N 1988 $^{\mathbf{6}}$ & $20.3 \%$ & $79.7 \%$ \\
\hline Pralhad.k 1993 $^{7}$ & $16.9 \%$ & $83.10 \%$ \\
\hline Kellie.M 1998 $^{\mathbf{2}}$ & $22 \%$ & $78 \%$ \\
\hline Daniel et al $\mathbf{1 9 9 9}^{\mathbf{9}}$ & $29 \%$ & $71 \%$ \\
\hline Present study & $11.68 \%$ & $88.31 \%$ \\
\hline
\end{tabular}

In present study higher rate of LSCS deliveries was encounter with unengaged head. Nearly $15.87 \%$ of patients had LSCS in this group compared with $8 \%$ in engaged group. Similar results were also noted in other studies $[6,8,10-13]$

Table 8: Comparison of mode of delivery in unengaged groups at the onset of early labour in primigravidae

\begin{tabular}{|l|l|l|l|l|l|l|}
\hline & Lakshmi.I & Pralhad.k & Sadiqua.N & Kellie.M & L.G.H & Present \\
\hline Unengaged head & 84.66 & 83.1 & 79.7 & 78 & 37.55 & 88.30 \\
\hline Vaginal delivery & 87 & 96.2 & 57 & 27 & 67 & 78.30 \\
\hline Instrumental & 3.3 & - & 24.4 & 43 & 7 & 5.7 \\
\hline L.S.C.S & 6.7 & - & 18.8 & 9.7 & 20 & 15.8 \\
\hline
\end{tabular}

LSCS rate were higher when patient presented with fetal head at -3 or above level. When head was floating more than $50 \%$ needed LSCS, While LSCS rate was $10 \%$ \& $25 \%$ when presentation was -3 \& -2 respectively. Results were comparable with other studies [14].

The mean birthweight among primigravida in the unengaged group is $2.77 \mathrm{~kg}$ higher than in the engaged group which was $2.06 \mathrm{~kg}$.

$78.3 \%$ of patients among the unengaged group, had normal vaginal delivery, however the unengaged group had a higher incidence of instrumental delivery and L.S.C.S,one of the reasons for the higher operative delivery rate in the head not engaged group is that patients with suspected or actual mild disproportion who were given a trial of labour were not excluded from the study.

\section{Conclusion}

Although many obstetricians believe that nulliparous patients present mostly with engaged fetal heads in active labour, this study and others indicate that most nulliparous patients present with an unengaged fetal head in active labour.

This finding allows the clinician to be more optimistic regarding vaginal delivery of nulliparous patients who present with an unengaged vertex in active phase of labour and avoid hasty decisions toward cesarean delivery. The results of this study have provided further evidence that abdominal palpation of the fetal head is an important component in the evaluation of women undergoing labour, since the prediction of successful vaginal delivery is more with abdominal criteria. Hence, in nulliparous patients a high station at the onset of labour is not necessarily an omnious finding, even though the incidence of arrest disorders are higher when station is -3 , or floating ,obstetricians can still be optimistic towards vaginal delivery.

\section{Funding: Nil}

Conflict of interest: Nil

Permission from IRB: Yes 


\section{References}

1. Qureshi NS, Saleem F, Riaz S. Primigravida with non engaged foetal head at term: an audit of delivery outcome. Ann KE Med Coll 1999;5:177-9.

2. Murphy K, Shah L, Cohen WR. Labour and delivery in nulliparous women who present with an unengaged foetal head. J Perinatol. 1998 Mar-Apr;18(2):122-5

3. Percival R: Holland Brews Manual of Obstetrics. Thirteenth edition .Churchill, London, p.133 .

4. Donald I : Practical Obstetric Problems. Fourth edition . Lyoyd-Luke,London ,p.466.

5. R.V.Thenmozhi, Lakshmi I . Study of influence of engagement of fetal head in primigravidae on the onset and outcome of labour. Journal of Obstet and Gynaecol of India 1984;1060-64

6. Jafarey SN .Unengaged foetal head in Pakistani primigravida : frequency and outcome. Asia Oceania $J$ Obstet Gynaecol 1988;14:13-6

7. Kushtagi P, Dhall GI , Dhall K -Pattern of cervical dilatation in normal labour.J Obstet Gynaecol India 1989 ; 39 :601-5.
8. Murphy, Shah, Cohen .Labour and delivery in nulliparous women who present with an unengaged fetal head .Journal of perinatology vol.18,No. 2,1998

9. Daniel R ,Blakemore K.J.Station at onset of active labour in nulliparous patients and risk of Caesarean delivery .Obstet Gynaecol 1999;93:329-31.

10 A clinical study of outcome of labour in primigravidae with unengaged vertex presentation at term or at the onset of labour ;L.G.H 1997

11. Roshan fekr D, Blakemore Kj, Lee j, Hueppchen NA, Witter FR. Station at onset of active labour in nulliparous patients and risk of cesarean delivery. Obstet Gynecol 1999;93:329-31.

12. Saropala N, Chaturachinda K. The relationship between head level on admission and mode of delivery in primigravidae. J Med Assoc Thai 1993;76:60-2.

13. Debby A, Rotmensh S, Girtler O,Sadan O, Golan A, Glezerman M.Clinical significance of floating foetal head in nulliparous women in labour. $\mathrm{J}$ Reprod Med 2003;48:37-40.

14. Murphy K, Shah L, Cohen WR. Labour and delivery in nulliparous women who present with an unengaged foetal head. J Perinatal 1998;18:122-5

\section{How to cite this article?}

Dayal S, Dayal A. Outcome of Labour in Nullipara at term with unengaged vertex. Int J Med Res Rev 2014;2(2):130-134. doi:10.17511/ijmrr.2014.i02.11 